\title{
RELAÇÃO DA FILOSOFIA COM A VIDA: DESAFIO A TRILHAR NA FORMAÇÃO PARA DOCÊNCIA NA EDUCAÇÃO BÁSICA
}

\author{
Sueny Nóbrega Soares de Brito ${ }^{1}$ \\ Maria Reilta Dantas Cirino ${ }^{2}$
}

\section{Resumo:}

A formação de professores/as para atuar no ensino básico no componente curricular de Filosofia é um dos aspectos responsáveis pelas discussões que se desenvolvem entre pesquisadores/as, formadores/as e profissionais do ensino. Diante as questões que norteiam os debates sobre a atuação do/a docente no ensino com os jovens do Ensino Médio, questionamos sobre: Qual relação o/a professor/a precisa trilhar com a Filosofia? Como relacionar a Filosofia à Vida dos/as estudantes e professor/a? O que podemos considerar indispensável na formação do/a professor/a? O referido artigo tem como objetivo discutir a formação do/a professor/a de Filosofia a considerar sua relação com a mesma, compreendendo a necessidade de relacionar no Ensino Médio a Filosofia com a Vida. Relatamos a discussão teórica sobre a formação do/a professor/a de Filosofia na Educação Básica a pensar sobre como o/a professor/a pode relacionar a Filosofia com a vida nas aulas da Educação Básica. A referida discussão é inspirada na pesquisa A EXPERIÊNCIA DO PIBID-FILOSOFIA CAICÓ-RN: NA CONSTRUÇÃO DE METODOLOGIAS PARA O ENSINO DE FILOSOFIA realizada no PROFILO/UERN/2019. Por fim, consideramos relevante para trilhar um caminho a partir da reflexão sobre relação da Filosofia com a vida, dialogar com Ortega Y Gasset, visto que o mesmo compreende a importância de pensarmos filosoficamente sobre o nosso viver para assim lidar melhor com os desafios que nos surpreendem.

Palavras-chave: Filosofia. Vida. Formação Docente.

\section{RELATIONSHIP BETWEEN PHILOSOPHY AND LIFE: A CHALLENGE TO BE PURSUED IN THE TRAINING OF TEACHERS IN BASIC EDUCATION}

\begin{abstract}
:
The formation of teachers to work in elementary education in the curricular component of Philosophy is one of the aspects responsible for the discussions that develop among researchers, trainers, and teaching professionals. Given the questions that guide the debates about the teacher's performance in teaching with high school youth, we question: What relationship does the teacher have with Philosophy? How to relate Philosophy to the lives of students and teachers? What can we consider essential in the teacher's formation? The objective of this article is to discuss the training of a Philosophy teacher considering his/her relationship with it, understanding the need to relate Philosophy to life in High School. We report the theoretical discussion about the formation of the philosophy teacher in elementary education, thinking about how the teacher can relate philosophy with life in basic education classes. The research THE EXPERIENCE OF PIBID-PHILOSOPHY CAICÓ-RN: IN THE CONSTRUCTION OF METHODOLOGIES FOR THE PHILOSOPHY EDUCATION conducted at PROFILO/UERN/2019 inspired this discussion. Finally, we consider relevant to dialogue with Ortega Y Gasset to build a path from the reflection on the relationship of Philosophy with life since he understands the importance of thinking philosophically about our lives to better deal with the challenges that surprise us.
\end{abstract}

Keywords: Philosophy. Life. Teacher Training.

\footnotetext{
${ }^{1}$ Maria Reilta Dantas Cirino. Doutorado em Educação/UERJ. Professora Adjunta IV do Departamento de Filosofa, da Universidade do Estado do Rio Grande do Norte - UERN, Campus Caicó e do Mestrado Profissional em Filosofia - PROF- FILO (Núcleo Caicó-UERN). E-mail: mariareilta@ hotmail.com.

${ }^{2}$ Sueny Nóbrega Soares de Brito. Mestrado Profissional em Filosofia pela Universidade do Estado do Rio Grande do Norte-UERN. Professora de Filosofa (SEEC/RN). Assessora da 10ª DIREC (SEEC/RN). E-mail: suenynobrega@ hotmail.com.
} 


\section{A FORMAÇÃO DOCENTE DO PROFESSOR DE FILOSOFIA}

A questão 'formação docente' tem sido discutida com frequência nos debates acadêmicos, as mudanças ocorridas na educação, nos diversos níveis de ensino, têm exigido uma formação adequada para demanda atual. Antes de discutirmos sobre a formação do curso de Filosofia vamos analisar o termo formação.

A palavra formação é propensa a várias interpretações, pode ser conjunto de cursos e graus obtidos por uma pessoa, instrução para se exercer uma determinada profissão, vem do "latim formatio, -onis, formação, forma" (HOUASISS, 2011, p. 448), sendo observada como modo de formar, podemos considerar a formação uma ação inacabada, que não finaliza e em qualquer profissão é um processo constante.

As transformações da sociedade contemporânea nos coagem a uma constante renovação de aprendizado nas variadas experiências da vida, seja de ordem profissional ou não. A formação inicial contribui significativamente para a vida profissional, mesmo assim há uma necessidade de continuidade, pois não é possível adquirir conhecimentos suficientes para solução de todos os problemas, nessa rapidez de atualizações que colocam a educação em mutação contínua.

Assim, consideramos que "Os processos de formação dão-se a conhecer, do ponto de vista do aprendente, em interações com outras subjetividades." (JOSSO, 2010, p. 35). Dessa forma, os encontros subjetivos ocorrem no decorrer da vida, sugerindo então o que podemos mencionar de necessidade formativa e autoformativa. Nessa perspectiva, "Formar-se é integrar numa prática o saber-fazer e os conhecimentos, na pluralidade de registros a que acabo de aludir. Aprender designa, então, mais especificamente, o próprio processo de integração." (JOSSO, 2010, p. 35).

A pluralidade de registros se encontra no social, cultural, político, econômico, psicológico, psicossociológico, e a formação é designada a contribuir para atuação do sujeito nas pluralidades que aparecem nas experiências cotidianas, aprendendo a partir das subjetividades e assim conseguindo administrar situações que vão além das formulações e soluções teóricas, mesmo que as utilizem como suporte.

Mais especificamente, a formação de professores/as requer a articulação entre teoria e experiência, sendo práticas individuais, depende de cada um/a o desenvolvimento

\begin{tabular}{|l|l|l|l|l|}
\hline Qevista Qialectus & Ano 9 & n. 20 & Outubro - Novembro 2020 & p. 154 - 174 \\
\hline
\end{tabular}


formativo, pois está relacionada ao desejo e capacidade de aprender. O processo formativo é complexo e se completa com a multiplicidade dos saberes teóricos adquiridos na formação inicial e continuada. A referida formação se torna específica por ajustar a formação acadêmica científica com a formação pedagógica, considerando também que ocorre a formação no formador/a e formando/a que vivenciam a prática com seus/as professores/as desde a infância, sendo influenciados/as pela subjetividade de principiantes e professores/as experientes.

É uma profissão prática que exige formação contínua, mais urgente do que qualquer outra profissão, já que as mudanças não ocorrem somente nos instrumentos de trabalho, mas principalmente, nos sujeitos envolvidos que estão em movimento, mais velozes que a própria tecnologia, considerando com mais rapidez o/a estudante da Educação Básica.

Assim, com relação à formação do/a professor/a podemos considerar que "[...] não é natural, mas construída, na definição pública de uma posição com forte sentido cultural, numa profissionalidade docente que não pode deixar de se construir no interior de uma pessoalidade do professor”. (NÓVOA, 2009, p. 03). O referido autor coloca cinco pontos indispensáveis na construção de um/a profissional de qualidade na docência:

- O conhecimento. [...] O trabalho do professor consiste na construção de práticas docentes que conduzam os alunos à aprendizagem.

- A cultura profissional. Ser professor é compreender os sentidos da instituição escolar, integrar-se numa profissão, aprender com os colegas mais experientes. [...]

- O tacto pedagógico. Nele cabe essa capacidade de relação e de comunicação sem a qual não se cumpre o ato de educar. E também essa serenidade de quem é capaz de se dar ao respeito, conquistando os alunos para o trabalho escolar. [...].

- O trabalho em equipe. Os novos modos de profissionalidade docente implicam um reforço das dimensões coletivas e colaborativas, do trabalho em equipe, da intervenção conjunta nos projetos educativos de escola.

- O compromisso social. Podemos chamar-lhe diferentes nomes, mas todos convergem no sentido dos princípios, dos valores, da inclusão social, da diversidade cultural. (NÓVOA, 2009, p. 03).

Os cinco pontos apresentados por Nóvoa (2009) nos impõem a pensar que a licenciatura, além da formação específica na construção do conhecimento relacionado à área de estudo, no caso dos conhecimentos filosóficos, não pode se esquivar da formação docente que requer considerar os pontos citados acima. Desses pontos destacamos a necessidade de desenvolver uma atitude intensiva no trabalho coletivo, observando que as situações atuais requerem soluções interdisciplinares que considerem as especificidades de conhecimentos hábeis quando utilizados em conjunto. Todos esses aspectos podem ser desenvolvidos

\begin{tabular}{|l|l|l|l|l|}
\hline Q Rovita Qialectus & Ano 9 & n. 20 & Outubro- Novembro 2020 & p. 154-174 \\
\hline
\end{tabular}


pelos/as profissionais da educação quando os/as mesmos/as se perceberem como agentes sociais, capazes de contribuir para transformações nos processos de formação, inclusive a própria formação do/a professor/a de Filosofia.

Para refletir sobre a formação do/a professor/a de Filosofia vamos pensar sobre sua atuação nos últimos 50 (cinquenta) anos, que, polemicamente, sobreviveu às oscilações de presença e ausência nas escolas brasileiras. A Lei de Diretrizes e Bases da Educação Nacional - LDB de 1961, Lei n. 4.024 (BRASIL, 1961), apresenta o ensino da Filosofia como optativo às escolas, que poderiam oferecer o conhecimento filosófico na diversidade dos conteúdos encontrados no currículo, sendo que poucas escolas praticaram essa tarefa, na realidade durante um determinado tempo, inclusive, à época do regime militar, o que predominou mesmo foi à ausência da Filosofia.

[...] há três momentos importantes a serem destacados: a presença da filosofia como disciplina acadêmica em uma conjuntura histórica na qual a cultura geral e humanística eram a tônica, que caracteriza o período anterior ao regime militar e que persiste, em grande medida, até 1968; um segundo momento período em que o regime militar prioriza a formação técnica e que se elimina o lugar que seria destinado à filosofia no Ensino Médio, e que se estende para além da década de 1990; e um terceiro momento, no qual se constrói o retorno do ensino de filosofia e se debate sobre sua contribuição para a formação crítica do jovem no Ensino Médio. (CARVALHO; SANTOS, 2010, p. 13).

Nesses três momentos, várias questões ideológicas, políticas e econômicas nortearam as discussões sobre o referido ensino, na ditadura foi considerado inapropriado a formação de jovens com instrução filosófica porque poderia conduzir ao pensamento crítico, e era associado ao comunismo pelos militares. E na formação técnica não pautava a necessidade de uma formação filosófica.

A discussão no terceiro momento inicia-se por entender a necessidade da Filosofia na formação do/a jovem crítico/a capaz de perceber seu universo e compreender sua capacidade de indagar sobre as coisas e não aceitar o estabelecido, partindo para o movimento de transformação.

O estudo da Filosofia permite a reflexão sobre a capacidade de perceber as várias dimensões existentes no momento de cada agir. "[...] a Filosofia é a possibilidade da transcendência humana, ou seja, a capacidade que só o homem tem de superar a sua imanência (que significa a situação dada e não escolhida)”. (ARANHA, 1986, p. 48).

\begin{tabular}{|l|l|l|l|l|}
\hline Q & Ano 9 & n. 20 & Outubro - Novembro 2020 & p. 154 - 174 \\
\hline
\end{tabular}


A ideia do ensino de Filosofia norteia o pensamento de contribuir para que o/a discente desenvolva sua transcendência, tornando-se um sujeito de projeto a partir da construção do seu destino, produzindo um novo projeto de vida, se emancipando na trajetória do conhecer.

No contexto atual é possível perceber a não identificação dos/as adolescentes no Ensino Médio pela disciplina filosófica, especialmente nos textos em que os/as referidos/as jovens não se sentem sensibilizados/as à leitura da Filosofia. Sendo considerada,

[...] uma disciplina no pensamento que nos leva a criar conceitos, é pensamento que confere significado à cultura na medida em que pratica sua síntese conceitual, sendo assim, em cada época, a sua verdade. O pensamento filosófico se considerado assim, não é apenas exercício de pensamento reflexivo e rigoroso, mas é, talvez principalmente criação. (ASPIS; GALLO, 2009, p. 14).

Dessa forma, é necessário incentivar o/a jovem a pensar por si mesmo, para que assim possa sentir-se aberto/a ao conhecimento, e na investigação, ser capaz de ler textos filosóficos, refletir, analisar, sintetizar e relacioná-los às problematizações do seu contexto.

A disciplina de Filosofia retorna ao componente curricular na Educação Básica, no contexto contemporâneo, a partir da LDB, n. 9.394, de 20 de dezembro de 1996. Com essa nova LDB, busca-se que os/as discentes do Ensino Médio demonstrem não só o domínio dos conteúdos dados e vistos na disciplina de Filosofia, como também que estes conhecimentos interfiram na formação positiva da cidadania. Assim, consideramos como finalidade do Ensino Médio, o que rege o Artigo 35, Inciso III “[...] o aprimoramento do educando como pessoa humana, incluindo a formação ética e o desenvolvimento da autonomia intelectual e do pensamento crítico". (BRASIL, 2011, p.23).

A Filosofia como disciplina do Ensino Médio se diferencia das demais, com as suas características próprias, por não ter uma linha cronológica seguida rigorosamente.

No entanto, não existe uma Filosofia - como há uma Física ou uma Química -, o que existem são filosofias, podendo o professor (a quem chamaríamos de filósofoeducador) privilegiar certas linhas de pensamento e de metodologia, sejam eles elas a dialética, a fenomenologia, a racionalista etc. Também, diferentemente das outras disciplinas, não há um 'começo', um pré-requisito para se introduzir a Filosofia, a não ser quando aos cuidados necessários com o estágio de competência de leitura e abstração dos alunos, bem como o universo de conhecimentos e valores que cada um deles já traz consigo. (BRASIL, 2002, p. 41-42. Grifo do autor.)

\begin{tabular}{|l|l|l|l|l|}
\hline Q & Ano 9 & n. 20 & Outubro - Novembro 2020 & p. 154 - 174 \\
\hline
\end{tabular}


A Filosofia no Ensino Médio aparece com uma proposta específica, buscando a partir do conhecimento do/a discente a construção do novo saber, proporcionando o desenvolvimento ético e político com eficiência. Mas, é possível perceber as divergências de Filosofias que dificultam o aprendizado no momento em que um/a professor/a trabalha apenas com temáticas, exemplo, o racionalismo, e outro/a relacionando à história da Filosofia com os temas atuais. Essa distinção provoca nos/as discentes desconfortos cognitivos no momento que mudam de professor/a de uma escola para outra ou até na mesma escola.

Dessa forma, que conteúdos filosóficos podem contribuir na formação do/a cidadão/ã conforme o apresentado pelo Ministério da Educação - MEC, para orientar a formulação dos currículos? Como, por exemplo, nos Parâmetros Curriculares Nacionais para o Ensino Médio - PCNEM (BRASIL, 2000), as Orientações Curriculares Nacionais para o Ensino Médio - OCNEM (BRASIL, 2006) e a mais recente Base Nacional Comum Curricular - BNCC (BRASIL, 2018a)? A Filosofia não é feita para ser um conhecimento pronto e acabado que é utilizado apenas para absorção e compreensão, deve sim compreender a História da Filosofia, mas a atitude do Filosofar é algo que só pode ser encontrado e realizado na vida, no cotidiano, em meio à sociedade em que o/a discente se encontra, ou seja, não adianta o/a filósofo/a-educador/a ser intitulado/a de mediador/a do conhecimento se este/a não mostra aos seus/suas estudantes que o conhecimento pode ser posto em prática seja em casa, na escola, na rua ou em qualquer lugar. Assim, os conteúdos devem ser trabalhados, desenvolvendo as necessidades das competências e habilidades apresentadas no PCNEM (BRASIL, 2000) que são as mesmas encontradas nas OCNEM (BRASIL, 2006). "Sistematicamente, pode-se manter a listagem das competências e das habilidades a serem desenvolvidas em Filosofia em três grupos: $1^{\circ}$ ) Representação e comunicação [...]. $2^{\circ}$ Investigação e compreensão [...]. $3^{\circ}$ Contextualização sociocultural” [...]. (BRASIL, 2006, p. 33-34).

Para trabalhar as habilidades apresentadas nos PCNEM (BRASIL, 2000) e OCNEM (BRASIL, 2006) é preciso selecionar os conteúdos conceituais específicos da disciplina de Filosofia, tendo cuidado em observar a essência filosófica e os objetivos da disciplina, analisando que os conteúdos não devem ser um "tal somatório manualesco e sem vida", “dogmático e antifilosófico", (BRASIL, 2006, p. 35), sendo apenas uma soma de preconceitos. Também fundamentada na LDB/1996, surge a Base Nacional Comum

\begin{tabular}{|l|l|l|l|l|}
\hline Qevista Qialectus & Ano 9 & n. 20 & Outubro - Novembro 2020 & p. 154 - 174 \\
\hline
\end{tabular}


Curricular- $\mathrm{BNCC}^{3}$, um documento que tem o intuito de contribuir na reorientação das práticas dos/as educadores/as, firmado nos princípios de trabalhar com competências capazes de estimular o/a jovem a desenvolver uma "[...] leitura de mundo sustentada em uma visão crítica e contextualizada da realidade, no domínio conceitual e na elaboração e aplicação de interpretações sobre as relações, os processos e as múltiplas dimensões da existência humana". (BRASIL, 2018a, p. 472).

A BNCC (BRASIL, 2018 ${ }^{a}$ ) orienta que cada área de conhecimento norteará suas atividades a partir das competências gerais e específicas, como também das habilidades, definindo como competência “[...] a mobilização de conhecimentos (conceitos e procedimentos), habilidades (práticas, cognitivas e socioemocionais), atitudes e valores para resolver demandas complexas da vida cotidiana, do pleno exercício da cidadania e do mundo do trabalho". (BRASIL, 2018a, p. 08).

A Filosofia se encontra na área das Ciências Humanas e Sociais Aplicadas e até as orientações atuais conforme o referido artigo, precisamente no " $§ 2^{\circ}$ A Base Nacional Comum Curricular referente ao Ensino Médio incluirá obrigatoriamente estudos e práticas de educação física, arte, sociologia e filosofia.” (BRASIL, 2017, p. 25). Nesse sentido, debates sobre o ensino de Filosofia na Educação Básica precisam continuar suas discussões em prol de garantir aos/as jovens da Educação Básica, o conhecimento filosófico apresentado como necessário na área das Ciências Humanas e Sociais Aplicadas.

A BNCC (BRASIL, 2018a) organiza as aprendizagens em 04 (quatro) áreas de conhecimento a seguir a proposta da LDB/1996, relatada no artigo 35-A: Linguagem e suas Tecnologias (língua portuguesa, arte, educação física, línguas estrangeiras modernas - inglês e espanhol), Matemática, Ciências da Natureza (biologia, física e química), Ciências Humanas e Sociais Aplicadas (geografia, história, física e sociologia) e Formação Técnica e Profissional. Tal forma de organização curricular tem o propósito de romper com a centralidade das disciplinas no currículo, favorecendo algumas possibilidades de integração curricular, para responder as demandas complexas da vida cotidiana. O currículo do Ensino Médio, em atendimento ao que preceitua o art. $\mathrm{n}^{\text {o }} 36$ da LDB/9.394/96, alterado pela Lei

\footnotetext{
${ }^{3}$ A Base Nacional Comum Curricular (BNCC) é um documento de caráter normativo que define o conjunto orgânico e progressivo de aprendizagens essenciais que todos os alunos devem desenvolver ao longo das etapas e modalidades da Educação Básica, de modo a que tenham assegurados seus direitos de aprendizagem e desenvolvimento, em conformidade com o que preceitua o Plano Nacional de Educação (PNE). (BRASIL, 2018a, p. 07).
}

\begin{tabular}{|l|l|l|l|l|}
\hline Q & Ano 9 & n. 20 & Outubro - Novembro 2020 & p. 154-174 \\
\hline
\end{tabular}


13.415/2017, fundamenta-se a partir da BNCC (BRASIL, 2018a), constituindo-se também de uma parte flexível, capaz de criar situações de trabalho mais colaborativas e organizadas de acordo com os interesses dos/as estudantes de modo que favoreçam seu protagonismo. Além da tradicional organização por disciplinas, a proposta do Novo Ensino Médio, evidencia possibilidades de flexibilização curricular da formação geral básica com intuito de facilitar a articulação entre as áreas do conhecimento. Nessa perspectiva, o Guia de Implementação do Novo Ensino Médio apresenta como flexibilização curricular as seguintes possibilidades: laboratórios, oficinas, clubes, observatórios, incubadoras, núcleos de estudo e núcleos de criação artística. (BRASIL, 2018b).

No processo de construção de uma proposta curricular para o Ensino Médio existem princípios básicos que fundamentam a sua elaboração, trazendo implícita uma visão sobre o tipo de sociedade que o projeto educacional deve contribuir para a formação do/a estudante. Nessa perspectiva indagamos: Que projeto educacional os/as professores/as almejam para os/as seus/as estudantes? Que projetos são almejados pelo sistema educacional federal? Que projeto educacional supre as necessidades dos/as jovens contemporâneos/as? As incertezas norteiam o proposto para o Ensino Médio no que se refere ao espaço da Filosofia, se a própria BNCC (BRASIL, 2018a) relata sobre a educação integral, contudo, não apresenta explicitamente o espaço da Filosofia. Esse aspecto, especialmente, é uma fragilidade que devemos nos preocupar, a ideia de pensar a Educação Básica sem a Filosofia nos remete a perceber a possibilidade de ser retirado do/a jovem o direito ao conhecimento filosófico, negando ao/à mesmo/a uma formação na perspectiva da educação integral.

Diante o exposto o que propomos na formação do/a professor/a de Filosofia é que esteja relacionada a pensar sobre a vida do/a estudante e docente, relacionando ao contexto de ambos a observar o que é possível fazer em presença da multiplicidade das perspectivas de experienciar a Filosofia, negando imposições doutrinárias, cuidando para que o currículo de Filosofia contemple a diversidade sem desconsiderar o/a docente em suas posições, mas apontando para várias Filosofias. Apresentar a totalidade proporciona ao/a estudante à formação da consciência crítica, capaz de desenvolver reflexões sobre a realidade, compreendendo a história da Filosofia, o posicionamento dos primeiros filósofos aos contemporâneos, refletindo sobre a diversidade do conhecimento filosófico e sua relação com a vida.

\begin{tabular}{|l|l|l|l|l|}
\hline Q & Ano 9 & n. 20 & Outubro - Novembro 2020 & p. 154 - 174 \\
\hline
\end{tabular}




\section{RELAÇÃO DA FILOSOFIA COM A VIDA: DESAFIO A TRILHAR NO ENSINO MÉDIO}

O ensino de Filosofia se torna complexo diante dos possíveis objetivos educacionais atribuídos ao mesmo e os fins filosóficos que permeiam as políticas ideológicas presentes na educação. A partir dos documentos legais como LDB/1996, PCNEM+ (BRASIL, 2002), OCNEM (BRASIL, 2006), DCN (BRASIL, 2013) e BNCC (BRASIL, 2018a), é possível questionar sobre que Filosofia queremos desenvolver na Educação Básica.

O objetivo da disciplina Filosofia não é apenas propiciar ao aluno um mero enriquecimento intelectual. Ela é parte de uma proposta de ensino que pretende desenvolver no aluno a capacidade para responder, lançando mão dos conhecimentos adquiridos, as questões advindas das mais variadas situações. Essa capacidade de resposta deve ultrapassar a mera repetição de informações adquiridas, mas, ao mesmo tempo, apoiar-se em conhecimentos prévios. (BRASIL, 2006, p. 29).

A Filosofia no Ensino Médio é muito mais do que transmissão de conteúdos, se tem o objetivo de desenvolver no/a estudante habilidades para soluções de problemas no seu cotidiano, então nos parece ser apresentados como necessários os conhecimentos filosóficos para o desenvolvimento de tais habilidades. Para o referido feito, percebemos a necessidade do filosofar que, mesmo sendo próprio de cada um/a para acontecer é preciso apoiar-se antes no pensamento de outros/as filósofos/as, e na aventura do processo com esforço significativo, o/a estudante pode se familiarizar com o modo de pensar rigoroso, desenvolvendo a experiência filosófica. “Aprender a filosofar é, portanto, aprender a perguntar. A Filosofia é, assim, um saber que incita o pensamento a despertar-se sempre." (SOFISTE, 2007, p. 07). E nessa experiência nossos/as jovens aprendem a indagar e não aceitar o estabelecido, instigando seu pensar.

$\mathrm{Na}$ tarefa de provocar os/as jovens a pensarem a partir da discussão filosófica mencionamos Sócrates na escrita de Platão, ao apresentar que sua atividade com os/as ouvintes tinham a finalidade de parir conhecimento, como se fosse a arte de uma experiente parteira.

[...] A minha arte obstétrica tem atribuições iguais às das parteiras, com a diferença de eu não partejar mulher, porém homens, e de acompanhar as almas, não os corpos, em seu trabalho de parto. Porém a grande superioridade da minha arte consiste na faculdade de conhecer de pronto se o que a alma dos jovens está na iminência de conceber é alguma quimera e falsidade ou fruto legítimo e verdadeiro. Neste particular, sou igualzinho às parteiras: estéril em matéria de sabedoria, tendo grande

\begin{tabular}{|l|l|l|l|l|}
\hline Qevista Cialectus & Ano 9 & n. 20 & Outubro - Novembro 2020 & p. 154 - 174 \\
\hline
\end{tabular}


fundo de verdade a censura que muitos me assacam, de só interrogar os outros, sem nunca apresentar opinião pessoal sobre nenhum assunto, por carecer, justamente, de sabedoria. E a razão é a seguinte: a divindade me incita a partejar os outros, [...]. (PLATÃO, 2001, p. 47).

A diferença principal na arte citada por Platão é que Sócrates praticava o parir da alma. Compreendendo que o mesmo não queria dizer que havia um nascer constante de novas almas a partir de outras, mas que apresentava como produto da alma o saber, e é isso que Sócrates tenta ajudar aos jovens. Pensamos que na docência em Filosofia a principal atitude do/a professor/a é de provocar o parir do saber, do conhecimento em cada estudante.

A arte do parir o saber deixa orgulhoso qualquer professor/a que considere a Filosofia a partir desse aspecto, através da maiêutica ${ }^{4}$, o/a filósofo/a colhe o fruto da alma do/a jovem, quanto mais provoca seu/ua estudante a pensar mais se sente satisfeito/a por ser responsável pela arte completa, ou seja, por ter também plantado a semente na alma fértil. $\mathrm{O}$ diálogo conduzido pela ironia socrática contribui para fluir a construção do conhecimento no sujeito aprendente.

O diálogo que remete ao ensino de Filosofia citado no referido texto é o diálogo que a partir de questionamentos conduz o/a jovem a uma direção do conhecer. Nesse diálogo o/a docente precisa estar atento à digressão na qual o/a discente vai transportar-se, digredir faz parte do processo do conhecer, na digressão, o sujeito percebe sua própria ignorância e se dispõe ao novo.

[...] Sempre que se veem forçados, nalgum encontro particular, a argumentar a respeito das teses por eles rejeitadas, e a sustentar com brio por algum tempo a discussão, sem abandonar covardemente o campo: então, amigo, com todos eles se passa uma coisa muito interessante, pois acabam por se desgostarem de seus próprios argumentos; [...]. (PLATÂO, 2015, p. 87).

Nessa perspectiva de ensino de Filosofia, é possível provocar no/a estudante o rever de suas próprias ideias, para assim ser possível se afastar das mesmas, desconstruir o estabelecido anteriormente e construir o novo ainda sendo inacabado, nesse ato se dá o

\footnotetext{
4 "O maiêutico não pensa em dar uma explicação para origem e significado dos pares de conceitos por ele introduzidos". (GABIONETA, 2015, p. 263). Consiste em conduzir a busca pelo saber através da ironia e maiêutica. A ironia ocorre quando o/a professor/a pergunta, fingindo não saber, esperando que o/a estudante se esforce intelectualmente a pensar sobre o saber. A partir do diálogo com questionamentos Sócrates escutava atentamente seus discípulos e, considerando o pronunciado tentava convencê-los da importância de analisarem sua própria opinião, levando-os a refletirem de que a mesma não estava livre do equívoco, de não ser verdadeira.
}

\begin{tabular}{|l|l|l|l|l|}
\hline Q Povista Dialectus & Ano 9 & n. 20 & Outubro - Novembro 2020 & p. 154 - 174 \\
\hline
\end{tabular}


processo de digressão. Pensar o ensino de Filosofia nessa lógica de exercitar o/a estudante no caminho do desconstruir o seu pensar e refletir sobre o mesmo, remete-nos a analisar os desafios da prática em que o ensino de Filosofia se encontra inserido. Um contexto em que a carga horária de uma aula semanal, institucionalizada a mercê dos ideais governamentais, a Filosofia como disciplina está constantemente nos debates educacionais em análise de sua permanência. Além do contexto citado o/a professor/a se dividi em oferecer um conjunto de conceitos, definições, tendências filosóficas, pensadores/as ou temas, problemas, experiências filosóficas e no como fazer na disciplina de Filosofia.

Diante dos variados desafios enfrentados pelo/a professor/a de Filosofia na Educação Básica, parece-nos ser necessário antes de sua atuação como professor/a entender como se dá a sua relação com a Filosofia, como o/a mesmo/a a compreende. Mas, antes de apresentarmos nossa compreensão é interessante lembrar que a Filosofia é um tema vasto, a permanecer indeterminado, precisamos então nos concentrar em um caminho que nos guie a uma relação com a Filosofia. Perante vários caminhos decidimos pensar em uma resposta a partir das discussões filosóficas que trilham pela relação da Filosofia com a nossa vida. (ORTEGA Y GASSET, 2016). E indagamos como a Filosofia na Educação Básica pode se relacionar com a vida do/a estudante e professor/a?

$\mathrm{Na}$ vida humana os problemas são enfrentados, analisados e superados pelos “[...] contemporâneos que não são coetâneos, [...] alojados num mesmo tempo externo e cronológico, convivem três tempos vitais distintos." (ORTEGA Y GASSET, 2016, p. 34). A diferença na coetaneidade nos proporciona pensar os problemas em várias dimensões e tentar coletivamente encontrar soluções para os mesmos. Sabemos que encontramos uma dificuldade de relacionar as ideias dos/as estudantes com os/as professor/as. Por sermos de gerações diferentes, geralmente nos inclinamos a pensar que estamos fatalmente envolvidos/as a uma geração, a seu modo de pensar e agir. Parece que nos identificamos com uma geração e a adotamos como referência, mas para rever os problemas em conjunto com os/as jovens (nossos contemporâneos), parece ser interessante “[...] em vez de nos abandonarmos a essa fatalidade que nos aprisiona a uma geração, é preciso reagir contra ela renovando-se no modo juvenil da vida que sobrevém". (ORTEGA Y GASSET, 2016, p. 36).

Nesse sentido, a Filosofia experienciada pelos/as contemporâneos/as que inclui três gerações: os/as jovens, os homens e mulheres maduros/as e os/as velhos/as, se refaz a cada tempo, explorando o passado, ao passo que reelabora o presente e questiona o futuro. A

\begin{tabular}{|l|l|l|l|l|}
\hline Govista Qialectus & Ano 9 & n. 20 & Outubro - Novembro 2020 & p. 154 - 174 \\
\hline
\end{tabular}


produção filosófica pensada pelos/as contemporâneos/as a partir da relação com a vida humana é rica em:

[...] três grandes dimensões vitais, que convivem alojadas nele, queiram ou não, enredadas umas com as outras e, ao serem diferentes, necessariamente em essencial hostilidade. 'Hoje' é, para uns, vinte anos, para outros quarenta, para outros sessenta; e isso, que três modos de vida tão distintos tenham de ser o mesmo 'hoje', expõe manifestamente o dramatismo dinâmico, o conflito e o choque que constitui o fundo da matéria histórica, de toda convivência atual. [...] Somos todos contemporâneos, vivemos num mesmo tempo e atmosfera, mas construímos com sua formação em tempos diferentes. (ORTEGA Y GASSET, 2016, p. 33. Grifos do autor.).

Decerto, jovens e professores/as ao refletirem sobre problemas dos homens e mulheres, podem construir conhecimento que contribua para formação de ambos, mas nesse cenário indagamos como esses contemporâneos se relacionam com a Filosofia? Para seguirmos em busca dessa resposta antes precisamos espreitar sobre o que pensamos que seja Filosofia.

Na história da Filosofia observamos que os/as filósofos/as se ocupam a pensar problemas da própria vida, refletem sobre inquietações que lhe afetam, ou seja, não podemos separar a Filosofia da vida, considerando que "[...] a vida é a realidade radical da qual é preciso partir e com a qual se deve contar. [...]”. (SÁNCHEZ, 2010, 24). Para entendermos a Filosofia relacionada à vida, precisamos definir o que pensamos sobre a vida, não citamos nesse texto a vida nas dimensões biológica ou psíquica, nos referimos que a "[...] vida é o que somos e o que fazemos: é pois, de todas as coisas, a mais próxima de cada um.” (ORTEGA Y GASSET, 2016, p. 218). Sendo assim, cada um a percebe de uma determinada forma a estar sempre em posse de si mesmo, como dono de sua própria vida.

\footnotetext{
Vivemos aqui, agora - ou seja, nos encontramos num lugar no mundo e nos parece que viemos a este lugar liberrimamente. A vida, de fato, deixa uma margem de possibilidades dentro do mundo, mas não somos livres para estar ou não neste mundo que é o de agora. É possível renunciar à vida, mas se vivemos, não é possível escolher o mundo em que se vive. [...] Viver não é entrar de bom grado num lugar previamente escolhido a gosto, como se escolhe o teatro depois do jantar - mas é encontrar-se imediatamente, e sem saber como, caído, submerso, projetado num mundo impermutável, neste de agora. Nossa vida é antes de tudo a perpétua surpresa [...] (ORTEGA Y GASSET, 2016, p. 223).
}

Na aventura do viver nos deparamos com o inesperado; é nessa vida de surpresas que precisamos pensar filosoficamente sobre o nosso viver. Se "[...] nos é arremessada ou

\begin{tabular}{|l|l|l|l|l|}
\hline Q & Ano 9 & n. 20 & Outubro - Novembro 2020 & p. 154 - 174 \\
\hline
\end{tabular}


somos arremessados nela", (ORTEGA Y GASSET, 2016, p. 224), na vida, então precisamos pensar sobre ela e o que fazemos por ela. Não temos como prever acontecimentos que realmente nos surpreendem, podemos até pensar na rotina que enfrentamos todos os dias, ir ao trabalho, à escola, ainda assim somos arremessados/as em situações complexas que nos apanham de surpresa, nessa perspectiva fabricamos nosso viver incessantemente a cada surpresa que nos é lançada.

A "Vida é, a uma só vez, fatalidade e liberdade, é ser livre dentro de uma fatalidade dada". (ORTEGA Y GASSET, 2016, p. 246). Não recebemos nossa vida feita e por mais que a julgamos determinada, estamos à mercê de possibilidades que não são ilimitadas, mas requer decisão para assim fabricar o que chamamos de nossa vida: “[...] neste fazer eu vivo e sou, eu o decidi porque, entre as possibilidades que tinha diante de mim, acreditei que ocupar assim a minha vida seria o melhor.” (ORTEGA Y GASSET, 2016, p. 245).

A relação do/a estudante com a Filosofia pode ser administrada no âmbito de pensar filosoficamente sobre as possibilidades do fabricar o viver, não como algo que prevê o esperado, mas sendo capaz de possibilitar o fazer-se e refazer-se nas condições que lhe são dadas a considerar a liberdade do poder fazer e viver. "Viver é uma revelação, um não contentar-se com ser, mas compreender ou ver que se é - um inteirar-se. É o descobrimento incessante que fazemos de nós mesmos e do mundo ao redor." (ORTEGA Y GASSET, 2016, p. 219). Acreditando que a Filosofia está conectada ao viver e indagamos como na Educação Básica podemos contribuir para que o/a estudante perceba esta conexão? Podemos pensar em uma atitude filosófica do/a estudante? Como pensar essa atitude?

Em busca de uma atitude filosófica professores/as e estudantes podem iniciar com a atitude do filósofo que "[...] começa esvaziando seu espírito de crenças recebidas, convertendo-o numa ilha deserta de verdades [...]." (ORTEGA Y GASSET, 2016, p. 102), passando a duvidar do conhecimento estabelecido nos discursos apresentados aos/às mesmos/as no dia-dia, duvidar, pois,

[...] inclusive do que não se duvida de fato, mas poderia, em princípio, ser duvidável. Essa dúvida instrumental e técnica, que é o bisturi do filósofo, tem um raio de atuação muito mais ampla que a habitual desconfiança do homem, posto que, deixando de lado o duvidoso, se alarga até o duvidável. (ORTEGA Y GASSET, 2016, p. 102).

\begin{tabular}{|l|l|l|l|l|}
\hline Qevista Qialectus & Ano 9 & n. 20 & Outubro - Novembro 2020 & p. 154 - 174 \\
\hline
\end{tabular}


No ensino de Filosofia é possível docentes e discentes se fazerem na Filosofia a partir da abertura de se enveredar na dúvida do que está sendo posto como verdade e problematizar filosoficamente o saber. Apontando para a dúvida nos deparamos com o perguntar que nesse contexto é possível relacionar ao filosofar.

O filosofar se apoia na inquietude de formular e formular-se perguntas e buscar respostas (o desejo de saber). Isso pode sustentar-se tanto no interrogar-se do professor ou dos alunos e nas tentativas de respostas que ambos se deem, bem como no de um filósofo e suas respostas. [...]. O perguntar filosófico é, então, o elemento constitutivo fundamental do filosofar [...]. (CERLETTI, 2009, p. 20-21).

Os/as estudantes e professores/as de Filosofia se encontram em um mundo de situações agradáveis ou não, com problemas contemporâneos que envolvem o viver dos/as mesmos/as. O importante no meio do filosofar “[...] não é o fato de as coisas serem ou não corpos, mas nos afetarem, nos interessarem, nos acariciarem, nos ameaçarem e nos atormentarem" no viver (CERLETTI, 2009, p. 222). Assim pensamos que o ensino de Filosofia precisa provocar a inquietação a partir do que possivelmente afete ${ }^{5}$ o/a estudante como também e/ou nos aspectos apresentados pelos/as professores/as.

A inquietação a partir de um problema filosófico (independente do que a gere) provoca o exercício de pensar sobre o próprio pensamento; “[...] o ser do pensamento consiste não simplesmente em ser, mas em ser para si, em dar-se conta de si mesmo, em parecer ser para si mesmo." (ORTEGA Y GASSET, 2016, p. 188). Nesse sentido falamos do pensamento inquieto, em que o filósofo o utiliza para formular problemas. A Filosofia é uma maneira de exercitar a experiência do pensamento, não o mantendo em um ponto fixo, acomodado, fechado e acabado; é o pensamento ativo que não se aquieta com o que já foi pensado, mas que se propõe a repensar o que incomoda além de ser capaz de criar, a partir do que se expande no pensar.

Diante do problema identificado, o desafio para o/a professor/a de Filosofia é exercitar o passo do pensar junto com o filósofo da tradição; é considerar como indispensável a superação do antigo e a necessidade de pensar um novo conceito, visto o antigo conceito não mais dá conta de si e do outro no contexto do presente.

\footnotetext{
${ }^{5}$ Os afectos, de acordo com Deleuze estão ligados aos perceptos, é algo da ordem do devir. "São devires que transbordam daquele que passa por eles, que excedem as forças daquele que passa por eles. O afecto é isso. Será que a música não seria a grande criadora de afectos? Será que ela não nos arrasta para potências acima de nossa compreensão?” (PARNET, 2014, p.2).
}

\begin{tabular}{|l|l|l|l|l|}
\hline Qevista 2 ialectus & Ano 9 & n. 20 & Outubro - Novembro 2020 & p. 154 - 174 \\
\hline
\end{tabular}




\begin{abstract}
Quando digo que necessitamos de conceitos novos, refiro-me ao que temos de acrescentar - os velhos perduram, mas com um caráter subalterno. Se nós descobrimos um novo modo de ser mais fundamental, é evidente que necessitamos de um conceito do ser desconhecido antes - mas, ao mesmo tempo, esse nosso conceito novíssimo tem a obrigação de explicar os antigos, demonstrar a porção de verdade que lhes corresponde. (ORTEGA Y GASSET, 2016, p. 231).
\end{abstract}

Para acrescentar novos conceitos é preciso superar conceitos já formulados e para que isso ocorra necessitamos também de conservar nuances dos conceitos já formulados para assim acrescentarmos, então “[...] superar é herdar e acrescentar [...]” (ORTEGA Y GASSET, 2016, p. 231). Na Filosofia, especialmente no problematizar e analisar conceitos, é que acrescentamos algo no saber de cada um. Mesmo que a Filosofia se ocupe da formulação de problemas e criação de conceitos, estes não decorrem diretamente de uma técnica como se a mesma permitisse uma transposição do não-saber ao saber.

Herdar não significa que fazer Filosofia é repetir os/as filósofos/as, e sim é perceber o que foi ocultado na tradição filosófica e ao existir no interior das ideias já existentes é possível fazer um processo descontínuo, inverso aos outros sistemas filosóficos, referindo-se a valorizar o que foi esquecido, o que não foi pensado, isso sem deixar de lado o que já foi pensado (tradição filosófica).

$\mathrm{Na}$ relação com a tradição fillosófica o/a docente e o/a estudante podem experienciar situações de criação, invenção e recriação do pensar, transformando-se e transformando o outro.

O professor-filósofo e seus alunos-filósofos-potenciais conformam um espaço comum de recriação no qual as perguntas se convertem em problemas que olham em duas direções: para a singularidade de cada um no perguntar-se (e a busca pessoal de respostas) e para a universalidade do perguntar filosófico (e as respostas que os filósofos se deram ao longo do tempo). Em um curso filosófico, essas direções confluem e se alimentam mutuamente. (CERLETTI, 2009, p. 32)

Pensar o ensino de Filosofia, o despertar um espaço de recriação de problemas contribui para que o/a estudante possa se afetar e assim aproveitar possibilidades de fazer-se no viver, configurando-se em processo de perceber a si mesmo/a como também a potencialidade do outro no exercício do pensamento.

Para enfrentar o desafio do ensino de Filosofia na Educação Básica é preciso pensá-lo de forma filosófica, ao planejar o/a professor/a de Filosofia deverá estar atento/a a:

\begin{tabular}{|l|l|l|l|l|}
\hline Qenista Qialectus & Ano 9 & n. 20 & Outubro - Novembro 2020 & p. 154 - 174 \\
\hline
\end{tabular}


[...] resolver o problema de ensinar filosofia em situações diversas. Não alguém que tenha meramente 'ferramentas' para ensinar, mas alguém que seja capaz de avaliar os supostos que acompanham as distintas ferramentas (filosóficas e pedagógicas, mas também sociais, de gênero, culturais, etc.) [...]. (CERLETTI, 2009, p. 63. Grifo do autor.)

Também precisa observar que o ensino de Filosofia ocorre em escolas que se caracterizam em espaços nem sempre adequados para se desenvolver o ensino, com uma carga horária reduzida ao mínimo de tempo para uma disciplina, com um número elevado de estudantes caracterizados em um universo diversificado.

Certamente as aulas de filosofia não se destinam a formar especialistas, função essa do Ensino Superior, nem atrair alunos para aqueles cursos. A atenção do professor de filosofia deve orientar-se para todos os estudantes, para aqueles que serão comerciantes, profissionais liberais, políticos, artistas, executivos, etc.; pessoas que, além de suas profissões, pertencem a uma família, a uma comunidade, são seres humanos situados num tempo espaço, capazes de refletir a respeito das suas circunstâncias, projetos, escolhas e modos de atuação. (ARANHA, 2000, p. 115)

Na prática docente é preciso estar atento/a às facetas que permeiam o ensino de Filosofia no que se refere à diversidade de situações, espaços e sujeitos envolvidos/as no processo. Para enfrentar esses obstáculos o/a professor/a pode oferecer condições para que os/as estudantes possam se reconhecer no exercício do pensar filosoficamente, como também em suas relações com os outros. O desafio a que nos propomos em nossa pesquisa é de pensar como oferecer essas condições e como a formação dos sujeitos de pesquisa na experiência do Subprojeto de Filosofia/UERN/Campus Caicó, contribuiu para a construção de metodologias que possam aproximar os/as estudantes da Educação Básica ao exercício do ensino da Filosofia, no sentido de que contribuam para a relação/desejo de filosofar dos/as estudantes. É possível encontrar um método que supra essa necessidade do professor de Filosofia? Que caminhos podemos pensar que contribuam para o pensar filosófico na Educação Básica?

Para enfrentar o debate sobre metodologia de ensino de Filosofia é interessante começarmos pensando no próprio termo método. “A palavra método é de origem grega e é composta por duas palavras: a preposição metá, que significa 'em meio a', 'junto a', 'entre' e o substantivo hodós, com o significado de caminho, passagem, viagem." (GUIDO; GALLO; KOHAN, 2013, p. 101. Grifo do autor.). Dessa forma, podemos perceber que o caminho se faz ao caminhar, então a viagem para encontrar uma metodologia que nos ajude a vivenciar a

\begin{tabular}{|l|l|l|l|l|}
\hline Q & Ano 9 & n. 20 & Outubro - Novembro 2020 & p. 154 - 174 \\
\hline
\end{tabular}


Filosofia com os/as jovens do Ensino Médio também será pensada ao caminhar. Podemos também pensar nos caminhos que já foram traçados pelos/as professores/as que atuam na Filosofia, especialmente na Educação Básica, para trilhar outros caminhos. Não repetimos os mesmos, porque não somos os mesmos, vivenciamos outros contextos e continuamente não seremos os mesmos, estamos em constantes mudanças nas formas de pensar e ser.

A Filosofia na perspectiva de inquietar-se com o viver, se caracteriza pela reflexão, a "[...] envolver a sensibilidade para admirar-se diante das coisas, do mundo, dos outros de si mesmo. [...] Admirar implica uma espécie de análise, de observação, de crítica e criatividade para que a atividade de pensamento se desenvolva". (GHEDIN, 2009, p. 43-44). Porém, pensamos como tocar o outro a esse inquietar-se? É possível esse toque? Os primeiros filósofos perplexos diante das dificuldades ocultadas na natureza avançaram pouco a pouco em busca de entender os fenômenos naturais explicados pela mitologia, que não saciavam as inquietações dos mesmos. Os/as jovens contemporâneos se encontram em uma realidade bem diferente daqueles filósofos naturalistas, muitos recursos tecnológicos e imediatos atravessam seu cotidiano, e chamam sua atenção. Nesse sentido, como tocá-los ao pensar filosófico? A pensar sobre si mesmo? A inquietar-se com o mundo?

"O interesse pela reflexão filosófica, assim como por qualquer outro assunto, só poderá ser despertado se os conteúdos se revelarem significativos para o sujeito da aprendizagem". (RODRIGO, 2009, p. 38). Então um dos cuidados do/a docente além da metodologia é com o conteúdo, que precisa estar relacionado com a estrutura cognitiva dos/as aprendentes e ter significado com os conhecimentos que os/as mesmos/as já se relacionaram. $\mathrm{Na}$ tentativa de experienciar o pensamento filosófico, docente e estudante compõem o mesmo espaço de pensar sobre o problema que se dispõem a refletir, juntos/as podem desencadear reflexões inéditas capazes de contribuir para outros debates filosóficos.

Nesse sentido, ao planejar, o/a docente precisa estar atento/a às novas inquietações dos/as estudantes, pois os diálogos na sala de aula podem encaminhar pensamentos inesperados conforme o planejado do/a docente. Isso não significa que não devemos planejar, ao contrário, o novo surgirá de forma hábil se tiver algo para superar. Os/as estudantes poderão contribuir para o planejar, na medida que se envolverem com o debate que a Filosofia propõe sobre determinado problema e assim inquietar-se e propor outras interrogações.

\begin{tabular}{|l|l|l|l|l|}
\hline Q Rovita Oialectus & Ano 9 & n. 20 & Outubro- Novembro 2020 & p. 154-174 \\
\hline
\end{tabular}


A forma como o/a docente encaminha a relação do/da estudante com a Filosofia contribui para o exercício filosófico, essas experiências podem conduzir o/a estudante a filosofar.

Filosofar é atrever-se a pensar por si mesmo, e fazê-lo requer uma decisão. Há que se atrever a pensar, porque isso supõe uma maneira nova de se relacionar com o mundo e com os conhecimentos, e não meramente reproduzi-los. E isso implica incerteza. Pensar supõe que há algo novo que se põe em jogo. (CERLETTI, 2009, p. 80).

Cada disciplina requer um pensar específico, a matemática requer pensar matematicamente, a história, historicamente, e a Filosofia não seria diferente, é preciso pensar filosoficamente para compreender seus conhecimentos e se dispor ao desejo do novo, do estranho. Nessa perspectiva, o/a docente precisa estar atento a uma metodologia “[...] que leve à reflexão filosófica para o universo conhecido e familiar dos alunos, desse modo, o universo tão distante, abstrato e complexo da Filosofia torna-se mais próximo, mais acessível e, por isso, muito mais interessante aos jovens estudantes.” (BULHÕES, 2012, p. 05).

No entanto, são nítidos os desafios e dificuldades no que se refere à construção de um caminho para o ensino de Filosofia que afete o/a outro/a, que o/a leve a se atrever a pensar filosoficamente. Em nossa discussão consideramos ser necessário perceber que “[...] o trabalho do cuidado, do pensamento, da Filosofia, começa sempre pelo si mesmo; não há como provocar certo efeito no outro se antes não se fez esse trabalho consigo mesmo [...]" (KOHAN, 2009, p. 38). Por isso, o/a ensinante para provocar a inquietação no outro, o atrever-se a pensar precisa antes ter provocado em si mesmo e para a referida ação é preciso então pensar numa formação que contemple a inquietação de si mesmo.

\section{CONSIDERAÇÕES FINAIS}

O ensino de Filosofia no Ensino Médio é considerado complexo, visto que além da pluralidade de como os/as professores/as se relacionam com a Filosofia, ainda há a questão da diversidade de escolas, de jovens, principalmente quando iniciam sua relação com o conhecimento filosófico. Nessa complexidade pensamos que o/a professor/a de Filosofia precisa estar atento/a as especificidades da Filosofia, as orientações legais para o referido ensino, como também as relações sociais, culturais, históricas dos/as estudantes.

\begin{tabular}{|l|l|l|l|l|}
\hline Q & Ano 9 & n. 20 & Outubro - Novembro 2020 & p. 154 - 174 \\
\hline
\end{tabular}


Na perspectiva de relacionar a Filosofia à vida, ao viver nos acompanhamos com o filósofo Ortega Y Gasset (2016) que nos convida a pensar que viver é uma revelação e isso implica ao não contentar-se com o simplesmente viver, o autor citado nos convida a pensar sobre a vida, a filosofar sobre a vida que nos é arremessada, como também buscar incansavelmente possibilidades de nos fazer.

Nesse sentido, nosso texto apresenta reflexões sobre a formação do/a professor/a de Filosofia, acreditando na possibilidade de contribuir para a construção de saberes capazes de auxiliar o/a docente a proporcionar aos/às estudantes da Educação Básica uma relação com a Filosofia de forma significativa a considerar sua relação com a vida. Nossa reflexão não termina com esse texto, precisamos unir esforços intelectuais e críticos sobre a educação no Ensino Médio no que se refere como pensar a relação dos/as docentes e discentes com a Filosofia e a vida, a propor uma formação filosófica que subsidiem nossos/as jovens a pensar sobre os problemas sociais, políticos, culturais, psíquicos e outros do seu cotidiano?

\section{Referências}

ARANHA, Maria Lúcia de Arruda. Filosofia no ensino médio: relato de uma experiência. In: GALLO, Sílvio; KOHAN, Walter Omar (Orgs.). Filosofia no ensino médio. 3 ed. Petrópolis, RJ: Vozes, 2000, p. 112-128.

ARANHA, Maria Lúcia de Arruda. Filosofando: introdução à filosofia. São Paulo: Moderna, 1986.

ASPIS, Renata Pereira Lima; GALLO, Sílvio. Ensinar filosofia: um livro para professores. São Paulo: Atta Mídia e Educação, 2009.

BRASIL. BNCC. Base Nacional Comum Curricular. 2018a. Disponível em: <file:///C:/Users/Cliente/Downloads/BNCC_14dez2018_site.pdf>. Acesso em: 09 de janeiro de 2019.

. Guia de implementação do novo ensino médio. 2018b. Disponível em: <file:///C:/Users/Cliente/Desktop/SUENY\%20NOTEBOOK\%202018/Guia\%20Implementa\% C3\%A7\%C3\%A3o\%20NEM.pdf >. Acesso em: 09 de janeiro de 2019.

LDB: Lei de diretrizes e bases da educação nacional. Brasília : Senado Federal, Coordenação de Edições Técnicas, 2017. Disponível em: <http://www2.senado.leg.br/bdsf/bitstream/handle/id/529732/lei_de_diretrizes_e_bases_1ed.p df.>. Acesso em: 04 de janeiro de 2019.

\begin{tabular}{|l|l|l|l|l|}
\hline Qevista Qialectus & Ano 9 & n. 20 & Outubro - Novembro 2020 & p. 154 - 174 \\
\hline
\end{tabular}


LDB: Lei de Diretrizes e Bases da Educação Nacional: Lei n. 9.394, de 20 de dezembro de 1996, que estabelece as diretrizes e bases da educação nacional. 6. ed. Brasília: Câmara dos Deputados, Edições Câmara, 2011.

. Ministério da Educação, Secretaria de Educação Média e Tecnológica. Ciências Humanas e suas tecnologias. PCN+: Ensino Médio: orientações educacionais complementares aos Parâmetros Curriculares Nacionais. Brasília: MEC; SEMTEC, 2002.

Ministério da Educação e do Desporto. Secretaria de Educação Fundamental. Parâmetros curriculares Nacionais: ensino médio. Brasília: MEC/SFE, 2000.

Ministério da Educação e do Desporto. Ciências humanas e suas tecnologias, Secretaria de Educação Básica. Orientações curriculares para o Ensino Médio. Brasília: MEC/SFE, 2006, v 3.

Diretrizes Curriculares da Educação Básica. Ministério da Educação. Secretária de Educação Básica. Diretoria de Currículos e Educação Integral. - Brasília: MEC, SEB, DICEI, 2013. Disponível em: < http://portal.mec.gov.br/docman/julho-2013-pdf/13677diretrizes-educacao-basica-2013-pdf/file>. Acesso em: 05 de janeiro de 2018.

BULHÕES, Fernanda. Filosofia e seu Ensino: reflexões e "produtos" dedicados aos professores de Filosofia no Ensino. 2012. UFRN. Disponível em: < http://arquivos.info.ufrn.br/arquivos/20121780809ce9113962573ffbb7c0214/fernandaFilosofi a_e_seu_Ensino.pdf >. Acesso em: 16 de maio de 2018.

CARVALHO, Marcelo; SANTOS, Marli dos. O ensino de filosofia no Brasil: três gerações. In: CORNELLI, Gabriele; CARVALHO, Marcelo; DANELON, Márcio. Filosofia: ensino médio. Ministério da Educação, Secretaria de Educação Básica, 2010. p. 13-44. (Coleção Explorando o Ensino; v. 14), p. 13-44.

CERLETTI, Alejandro. A. O ensino de filosofia como problema filosófico. Tradução de Ingrid Müller Xavier. Belo Horizonte: Autêntica 2009. (Coleção Ensino de Filosofia).

HOUASISS, Antônio. Dicionário Conciso.. São Paulo: Moderna, 2011.

GABIONETA, Robson. a maiêutica socrática como 'união' de teorias no Teeteto. Revista Classica, v. 28, n. 2, p. 35-45, $2015 . \quad$ Disponível em: <https://revista.classica.org.br/classica/article/view/326/301>. Acesso em: 02 de março de 2018.

GHEDIN, Evandro. Ensino de Filosofia no Ensino Médio. 2 ed. São Paulo: Cortez, 2009. (Coleção Docência em Formação. Série Ensino Médio)

GUIDO, Humberto; GALLO, Sílvio; KOHAN, Walter Omar. Princípios e possibilidades para uma metodologia filosófica do ensino de filosofia: história, temas, problemas. In:

\begin{tabular}{|l|l|l|l|l|}
\hline Q Rovista Qialectus & Ano 9 & n. 20 & Outubro - Novembro 2020 & p. 154-174 \\
\hline
\end{tabular}


CARVALHO, Marcelo; CORNELLI, Gabriele. Ensinar filosofia. (Orgs.). Cuiabá, MT: Central de Texto, 2013. Vol 02, p. 101-128. Disponível em: < https://educapes.capes.gov.br/bitstream/capes/401647/1/Filosofia\%20e\%20forma\%C3\%A7\% C3\%A3o_Vol_2.pdf>. Acesso em: 30 de junho de 2018.

JOSSO, Marie-Christine. Experiência de vida e formação. Trad. José Cláudio, Júlia Ferreira. 2 ed. São Paulo: Paulus, 2010. (Coleção Pesquisa (auto)biográfica \& Educação. Série Clássicos das Histórias de Vida).

KOHAN, Walter Omar. Filosofia: O paradoxo de aprender e ensinar. Tradução de Ingrid Müller Xavier. Belo Horizonte: Autêntica, 2009. - (Coleção Ensino de Filosofia).

PARNET, Claire. Abecedário: entrevista feitas a Deleuze. Disponível em:< http://stoa.usp.br/prodsubjeduc/files/262/1015/Abecedario+G.+Deleuze> Acesso em: $13 / 03 / 2014$.

NÓVOA, António. Para uma formação de professores construída dentro da profissão. Portugal: Universidade de Lisboa. 2009. Disponível em: <http://www.revistaeducacion.mec.es/re350/re350_09por.pdf>. Acesso em: 08 de março de 2014.

ORTEGA Y GASSET, José. O que é a filosofía? Tradução de Felipe Denardi; posfácio de María Zambrano. Campinas, SP: Vide Editorial, 2016.

PLATÃO. Teeteto. In. Teeteto; Crátilo. Tradução direto do grego de Carlos Alberto Nunes. $3^{\text {a }}$ Edição Revisada. Belém-Pará: EdUFPA, 2001. Disponível em: <http://www.verlaine.pro.br/txt/platao-teeteto.pdf>. Acesso em: 02 de maio de 2017.

RODRIGO, Lidia Maria. Filosofia em sala de aula: teoria e prática para o ensino médio. Campinas, SP: Autores Associados, 2009. (Coleção formação de professores).

SOFISTE, Juarez Gomes. Sócrates e o ensino de Filosofia: Investigação Dialógica: Uma Pedagogia para a Docência de Filosofia. Petrópolis, RJ: Vozes, 2007.

SÁNCHEZ, Juan Escámez. Ortega y Gasset. Tradução: José Gabriel Perissé. Recife:Editora Massangana, 2010.

\begin{tabular}{|l|l|l|l|l|}
\hline Q & Ano 9 & n. 20 & Outubro - Novembro 2020 & p. 154-174 \\
\hline
\end{tabular}

